OPEN ACCESS

Edited by:

Scott T. Tagawa

Cornell University, United States

Reviewed by:

Eric A. Singer,

Rutgers Cancer Institute of New Jersey, United States

Eleonora Anna Mess,

Wroclaw Medical University, Poland

*Correspondence:

Guiliang Tang

sxtangzy@163.com

tThese authors have contributed equally to this work and as co-first authors

Specialty section:

This article was submitted to Genitourinary Oncology,

a section of the journal

Frontiers in Oncology

Received: 07 May 2019

Accepted: 29 July 2019

Published: 14 August 2019

Citation:

Wang X, Ni X and Tang G (2019)

Prognostic Role of

Platelet-to-Lymphocyte Ratio in

Patients With Bladder Cancer: A

Meta-Analysis. Front. Oncol. 9:757.

doi: 10.3389/fonc.2019.00757
Prognostic Role of

\section{Platelet-to-Lymphocyte Ratio in Patients With Bladder Cancer: A Meta-Analysis}

\author{
Xingmu Wang ${ }^{1+}$, Xiaoyan $\mathrm{Ni}^{1+}$ and Guiliang Tang ${ }^{2 *}$ \\ ${ }^{1}$ Center of Clinical Laboratory, Shaoxing People's Hospital, Shaoxing Hospital of Zhejiang University, Shaoxing, China, \\ ${ }^{2}$ Department of Urology, Shaoxing People's Hospital, Shaoxing Hospital of Zhejiang University, Shaoxing, China
}

Background: Many studies have been reported that platelet-to-lymphocyte ratio (PLR) may be associated with the prognosis of bladder cancer, but the results are inconsistent. Therefore, we performed a meta-analysis to evaluate the effect of pretreatment PLR on the prognosis of bladder cancer.

Methods: The databases PubMed, Embase, Cochrane Library, and Web of Science were searched. Pooled hazard ratios (HRs) and 95\% confidence intervals (Cls) were used to analyze the relationship between PLR and prognosis. Pooled odds ratios (ORs) and 95\% Cls were used to analyze the relationship between PLR and clinicopathological features. Publication bias was estimated using Begg's funnel plot asymmetry tests.

Results: A total of 8 studies comprising 3,303 patients were included in this meta-analysis. An elevated PLR was significantly associated with poorer overall survival (OS) $(\mathrm{HR}=1.26,95 \% \mathrm{Cl}=1.03-1.54, p=0.026)$, but not with cancer-specific survival (CSS) (HR $=1.15,95 \% \mathrm{Cl}=0.95-1.38, p=0.149)$, or recurrence-free survival (RFS) $(\mathrm{HR}=1.72,95 \% \mathrm{Cl}=0.79-3.75, p=0.175)$. In addition, high PLR was correlated with age $\geq 65$ years $(\mathrm{OR}=1.82,95 \% \mathrm{Cl}=1.24-2.67, p=0.002)$, whereas was not significantly correlated with sex, tumor grade, tumor stage, distant metastasis, or tumor size.

Conclusions: The pretreatment PLR could serve as a predicative biomarker of poor prognosis for patients with bladder cancer.

Keywords: meta-analysis, PLR, prognosis, bladder cancer, biomarker

\section{INTRODUCTION}

Bladder cancer is the 10th most common cancer worldwide, with an estimated 549,000 new cases and 200,000 deaths in 2018 (1). Approximately 75\% of all bladder cancer cases occur in men and incidence rates varies largely around the world (1). Basically, bladder carcinomas are classified as non-muscle invasive bladder cancer (NMIBC) (Ta/T1) and muscle-invasive bladder cancer (MIBC) (T2-T4). About $75 \%$ of patients have NMIBC and 25\% have MIBC or metastatic disease (2). Despite aggressive surgical treatment and improvements in therapeutic approaches for bladder cancer, survival outcome has not substantially improved, with high recurrence and mortality (3). 
Prognostication is essential for treatment decision making (4). Therefore, seeking a novel and effective prognostic biomarker is important for the improvement of survival outcomes.

Host inflammatory responses can greatly affect tumor development and progression (5). The systemic inflammatory status could be reflected by many blood biomarkers including $\mathrm{C}$-reactive protein (CRP), neutrophil-to-lymphocyte ratio (NLR) (6), platelet-to-lymphocyte ratio (PLR) $(7,8)$, and lymphocyteto-monocyte ratio (LMR) (9). Various serum and tissue biomarkers reflecting systemic inflammatory response show reliable prognostic value in cancer (6). PLR is calculated as platelet counts divided by lymphocyte counts. Previous studies have reported the prognostic value of PLR in various solid tumors, such as hepatocellular carcinoma (10), breast cancer (11), colorectal cancer (12), prostate cancer (13), and non-small cell lung cancer (14). Recently, several retrospective studies have evaluated the impact of PLR on the prognosis of bladder cancer patients (15-19). However, based on their findings, the current view of the prognostic role of PLR in bladder cancer is not yet clear. Therefore, we performed a meta-analysis to evaluate the effect of pretreatment PLR on the prognosis of bladder cancer.

\section{MATERIALS AND METHODS}

\section{Search Strategies}

This meta-analysis was carried out according to Preferred Reporting Items for Systematic Reviews and Meta-Analyses (PRISMA) Statement (20). The databases PubMed, Embase, Cochrane Library, and Web of Science were searched to March 2019. The citation lists of included studies were also examined. Search terms included "bladder cancer" or "bladder carcinoma" or "bladder neoplasm" or "bladder tumor," and "platelet to lymphocyte ratio," or "PLR," or "platelet-lymphocyte ratio." Ethical approval was waived because this was a meta-analytic study and we just collected the data from available publications.

\section{Inclusion and Exclusion Criteria}

The inclusion criteria were as follows: (1) bladder cancer was diagnosed from pathological examination; (2) a dichotomous cut-off value of the PLR was identified to classify the patients into high and low PLR groups; (3) studies assessed the association of PLR with overall survival (OS), cancer-specific survival (CSS), and/or recurrence-free survival (RFS); (4) studies provided sufficient information for calculating hazard ratio (HR) and 95\% confidence interval (CI); (5) published in English. The exclusion criteria were as follows: (1) case reports, conference abstracts, letters, editorials, reviews; (2) overlapping or duplicate studies; (3) irrelevant studies.

\section{Data Extraction and Quality Assessment}

The selection of studies was conducted independently by two investigators (XW, XN) and any discrepancies were resolved by consensus. The following information were extracted from each study: first author, publication year, country, case number, age, cut-off values, study design, treatment method, and survival outcomes. The Newcastle-Ottawa Scale (NOS) was applied to evaluate the quality of all included studies (21). The
NOS consisted of three parts: (a) selection (0-4 points); (b) comparability ( $0-2$ points); and (c) outcome ( $0-3$ points). The maximum score is 9 points and NOS scores $\geq 6$ were assigned as high-quality studies.

\section{Statistical Analysis}

Pooled HRs and 95\% CIs were used to analyze the relationship between PLR and prognosis. Pooled odds ratios (ORs) and 95\% CIs were used to analyze the relationship between PLR and clinicopathological features. Cochran's Q test and Higgins $I^{2}$ statistic were used to assess the heterogeneity among studies. A $P<0.10$ for $Q$-test or $I^{2}>50 \%$ for $I^{2}$ test suggested significant heterogeneity and then a random-effect model (DerSimonianLaird method) (22) was applied. Otherwise, the fixed-effect model (Mantel-Haenszel method) (23) was adopted. In addition, for the pooled HR estimates of OS and CSS, subgroup analysis by ethnicity, sample size, and cut-off value of PLR was conducted. Publication bias was estimated using Begg's funnel plot asymmetry tests (24). All analyses were carried out with the statistical software Stata, version 12.0 (Stata corporation, College Station, TX, USA). A two-sided $p<0.05$ was considered statistically significant.

\section{RESULTS}

\section{Search Results and Study Characteristics}

The flowchart of the literature selection process was shown in Figure 1. The initial retrieval of electronic databases identified 110 records; after duplicates were removed, 67 studies remained. After title and/or abstract examination, 44 papers were excluded and 23 records were evaluated by full-text reading. Fifteen full text studies were eliminated because of various reasons (Figure 1). Finally, 8 studies (15-19, 25-27) comprising a total of 3,303 patients, were included in this meta-analysis. The studies were published from 2015 to 2018 and were all retrospective studies. Of the 8 eligible articles, 3 studies $(18,25,26)$ were from China, and 1 each from Canada (16), Korea (17), UK (15), Japan (19), and Poland (27), respectively. The cut-off values of PLR ranged from 123 to 218 , with a median value of 150 . All studies had a NOS score $\geq 6$. The baseline characteristics of included studies were shown in Table $\mathbf{1}$.

\section{The Prognostic Value of PLR for OS}

There were 7 studies $(15-17,19,25-27)$ providing data for estimating the association between PLR and OS in patients with bladder cancer. As shown in Figure 2A and Table 2, the pooled estimate of the high PLR for OS was significant, with the pooled HR being 1.26 (95\% CI: $1.03-1.54, p=0.026)$ with significant heterogeneity $\left(I^{2}=81.3 \%\right.$ and $\left.P<0.001\right)$. Subgroup analysis revealed that PLR has significant prognostic value for OS with cut-off value of PLR $\geq 150$, whereas no significant prognostic significance was found regardless of ethnicity or sample (Table 2).

\section{The Prognostic Value of PLR for CSS}

A total of 4 studies $(16,17,19,27)$ reported the data on PLR and CSS. The combined HR and 95\% CI were: HR $=1.15,95 \%$ 


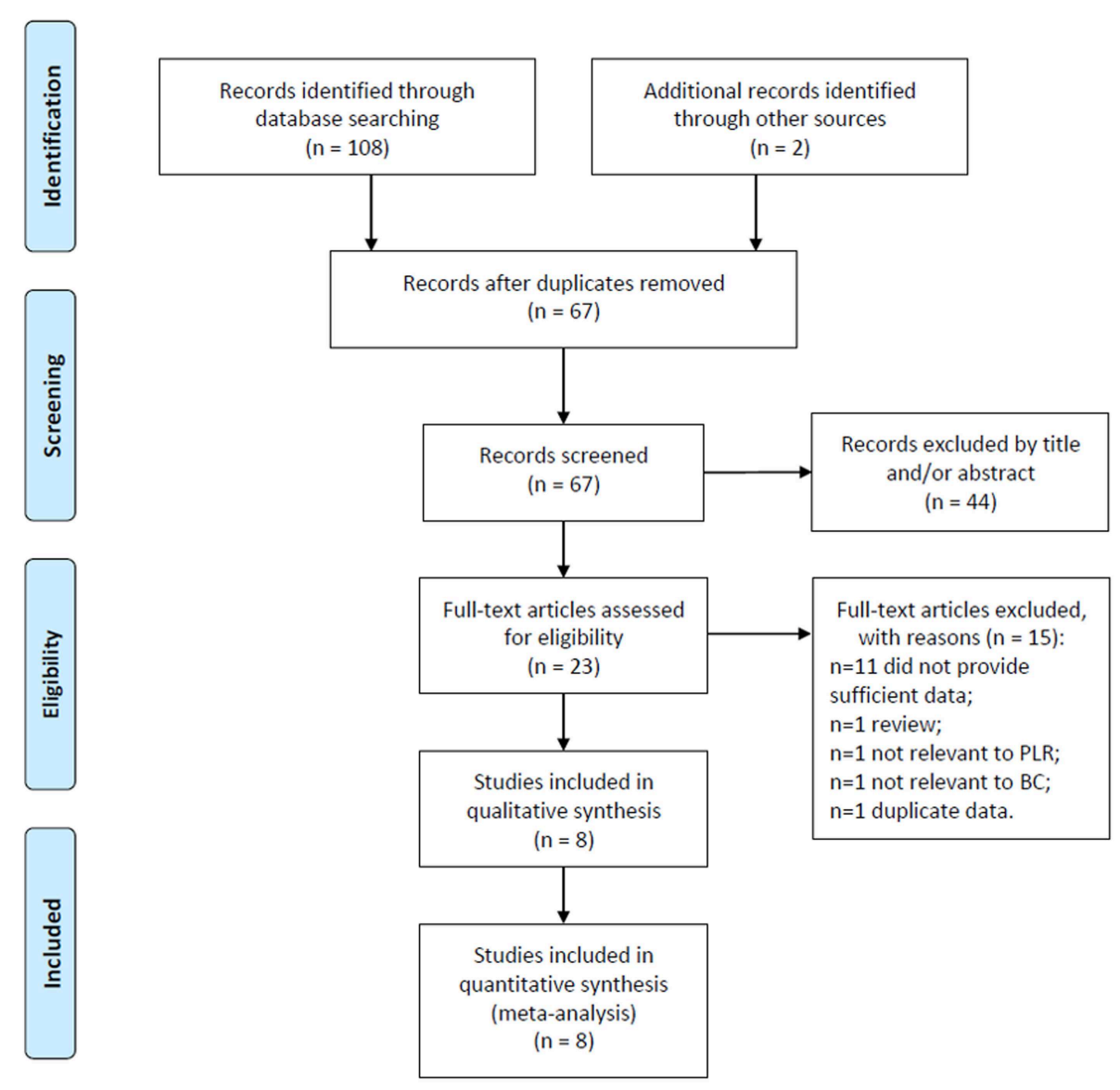

FIGURE 1 | Flow chart of the included studies.

TABLE 1 | Baseline characteristics of studies included in the meta-analysis.

\begin{tabular}{lllccccccc}
\hline References & Country & $\begin{array}{c}\text { Dominant } \\
\text { ethnicity }\end{array}$ & $\begin{array}{c}\text { Sample } \\
\text { size }\end{array}$ & $\begin{array}{c}\text { Median/mean } \\
\text { age (y) }\end{array}$ & $\begin{array}{c}\text { Study } \\
\text { design }\end{array}$ & $\begin{array}{c}\text { Treatment } \\
\text { Cut-off } \\
\text { value }\end{array}$ & $\begin{array}{c}\text { Study } \\
\text { period }\end{array}$ & $\begin{array}{c}\text { Survival } \\
\text { outcome }\end{array}$ \\
Bhindi et al. (16) & Canada & Caucasian & 418 & 70 & R & RC & 150 & $1992-2012$ & OS, CSS, RFS \\
score
\end{tabular}

NA, not available; RC, radical cystectomy; TURB, transurethral resection of bladder tumor; OS, overall survival; CSS, cancer-specific survival; RFS, recurrence-free survival.

$\mathrm{CI}=0.95-1.38, p=0.149$ and the heterogeneity was significant $\left(I^{2}=72.5 \%\right.$ and $\left.P=0.012\right)$. Subgroup analysis demonstrated that PLR showed significant prognostic impact on CSS in studies with sample size $\geq 200(\mathrm{HR}=1.21,95 \% \mathrm{CI}=1.05-1.39, p=0.007$, Figure 2B and Table 2).

\section{The Prognostic Value of PLR for RFS}

There were 2 studies $(16,18)$ presenting the data of PLR and RFS in bladder cancer. The pooled results indicated non-significant prognostic effect of PLR in RFS (HR $=1.72,95 \% \mathrm{CI}=0.79-3.75$, $p=0.175 ; I^{2}=83.5 \%, P=0.014$; Figure 2C and Table 2).

\section{The Association of PLR and Clinicopathological Factors}

Four studies $(15,18,25,27)$ reported the relationship between PLR and clinicopathological factors including sex, tumor grade, tumor stage, distant metastasis, age, and tumor size. As 


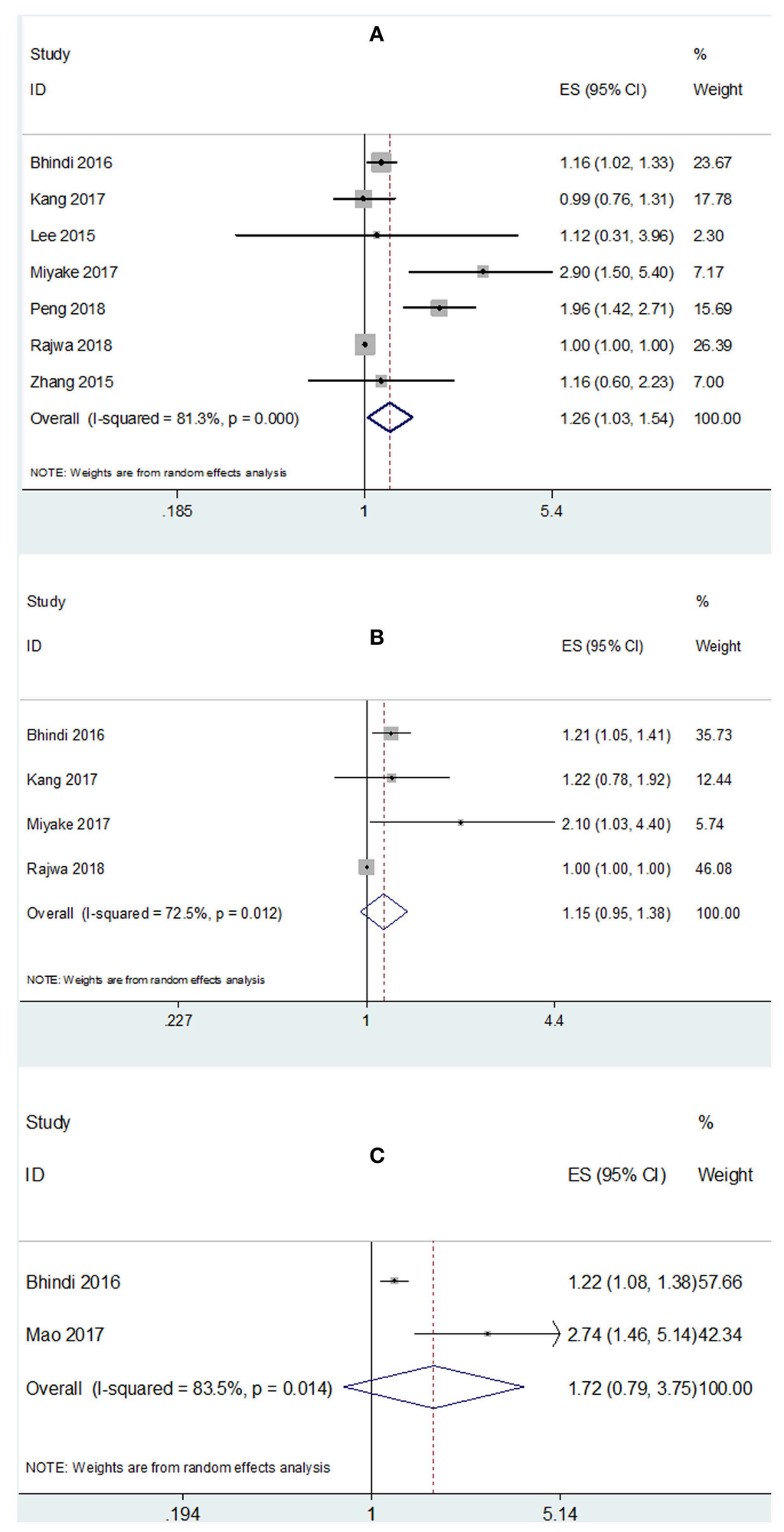

FIGURE 2 | Meta-analysis of the association between PLR and (A) OS, (B) CSS, and (C) RFS mortality of bladder cancer.

shown in Figure 3 and Table 3, high PLR was found to be significantly associated with age $\geq 65$ years $(\mathrm{OR}=1.82$, 95\% CI $=1.24-2.67, p=0.002)$, whereas PLR was not significantly correlated with sex $(\mathrm{OR}=1.03,95 \% \mathrm{CI}=0.7-$ $1.51, p=0.884)$, tumor grade $(\mathrm{OR}=1.62,95 \% \mathrm{CI}=0.56-$ $4.69, p=0.373)$, tumor stage $(\mathrm{OR}=1.92,95 \% \mathrm{CI}=0.97-3.79$, 
TABLE 2 | Subgroup analysis of the association between PLR and OS, CSS, RFS.

\begin{tabular}{|c|c|c|c|c|c|c|}
\hline Survival analysis & $\begin{array}{l}\text { No. of } \\
\text { studies }\end{array}$ & HR (95\% Cl) & $p$ & $I^{2}(\%)$ & $P$-value for heterogeneity & $\begin{array}{l}\text { Analysis } \\
\text { model }\end{array}$ \\
\hline \multicolumn{7}{|l|}{ OS } \\
\hline Total & 7 & $1.26(1.03-1.54)$ & 0.026 & 81.3 & $<0.001$ & Random \\
\hline \multicolumn{7}{|l|}{ Ethnicity } \\
\hline Asian & 4 & $1.56(0.96-2.54)$ & 0.074 & 80.9 & 0.001 & Random \\
\hline Caucasian & 3 & $1.06(0.94-1.29)$ & 0.369 & 57.5 & 0.095 & Random \\
\hline \multicolumn{7}{|l|}{ Sample size } \\
\hline$<200$ & 3 & $1.42(0.77-2.65)$ & 0.264 & 72.9 & 0.011 & Random \\
\hline$\geq 200$ & 4 & $1.27(0.95-1.72)$ & 0.11 & 81.4 & 0.005 & Random \\
\hline \multicolumn{7}{|l|}{ Cut-off value } \\
\hline$<150$ & 2 & $1.01(0.79-1.3)$ & 0.915 & 0 & 0.658 & Fixed \\
\hline$\geq 150$ & 5 & $1.37(1.06-1.77)$ & 0.017 & 87.5 & $<0.001$ & Random \\
\hline \multicolumn{7}{|l|}{ css } \\
\hline Total & 4 & $1.15(0.95-1.38)$ & 0.149 & 72.5 & 0.012 & Random \\
\hline \multicolumn{7}{|l|}{ Ethnicity } \\
\hline Asian & 2 & $1.42(0.97-2.08)$ & 0.073 & 35.6 & 0.213 & Fixed \\
\hline Caucasian & 2 & 1.09 (0.91-1.3) & 0.377 & 83.9 & 0.013 & Random \\
\hline \multicolumn{7}{|l|}{ Sample size } \\
\hline$<200$ & 2 & $1.32(0.66-2.67)$ & 0.434 & 74.9 & 0.046 & Random \\
\hline$\geq 200$ & 2 & $1.21(1.05-1.39)$ & 0.007 & 0 & 0.973 & Fixed \\
\hline \multicolumn{7}{|l|}{ Cut-off value } \\
\hline$<150$ & 1 & $1.22(0.78-1.91)$ & 0.387 & NA & NA & NA \\
\hline$\geq 150$ & 3 & $1.14(0.93-1.41)$ & 0.213 & 80.4 & 0.006 & Random \\
\hline \multicolumn{7}{|l|}{ RFS } \\
\hline Total & 2 & $1.72(0.79-3.75)$ & 0.175 & 83.5 & 0.014 & Random \\
\hline
\end{tabular}

NA, not available.

$p=0.06)$, distant metastasis $(\mathrm{OR}=1.07,95 \% \mathrm{CI}=0.27-4.16$, $p=0.927)$, or tumor size $(\mathrm{OR}=2.19,95 \% \mathrm{CI}=0.91-5.28, p$ $=0.08$ ).

\section{Publication Bias}

Publication bias was not significant in the current meta-analysis based on the plots of publication shown in Figure 4. The Begg's $p$ for OS, CSS, and RFS were $0.764,0.497$, and 0.317 , respectively.

\section{DISCUSSION}

In the present study, we comprehensively searched multiple databases and retrieved 8 studies including 3,303 patients with regard to the prognostic value of PLR for bladder cancer. To our knowledge, this study is the first meta-analysis to investigate the prognostic role and clinical relevance of PLR in patients with bladder cancer. The pooled data showed that a high PLR predicted poorer OS in bladder cancer, moreover, high PLR was correlated with patients aged 65 years and older. Taken together, this study indicated that the pretreatment PLR might be as a convenient and reliable biomarker in the prognosis of bladder cancer.

Recent studies have shown that the inflammatory nature of the tumor microenvironment plays a key role in tumor development, including initiation, growth, and metastasis (28,
29). It has been suggested that there is crosstalk between inflammatory responses and tumor progression (5). However, the potential mechanism of PLR affecting the survival of patients with bladder cancer is still largely unknown. This association may be explained by immune inflammation in the tumor microenvironment. Platelets can directly promote the growth of tumor cells by secreting vascular endothelial growth factor, basic fibroblast growth factor, platelet-derived growth factor and other angiogenesis and tumor growth factors (30-32). Platelet-derived micro vesicles can stimulate mitogen-activated protein kinases and promote tumor progression, metastasis, and angiogenesis in lung cancer cells (33). In addition, plateletderived nucleotides can promote tumor-cell transendothelial migration and metastasis via $\mathrm{P} 2 \mathrm{Y} 2$ receptor (34). In contrast, lymphocytes play an important role in $\mathrm{T}$ cell mediated antitumor response. Tumor infiltrating lymphocytes (TIL) are common inflammatory cells in the tumor environment and have been found to be involved in the anti-tumor immune response (35). In addition, high number of TILs have antitumor activity as judged by their favorable effect on cancer patients' survival (36). Therefore, the PLR combines the significance of platelet counts and lymphocyte counts and has the potential to be an effective prognostic biomarker.

Previous studies have shown the prognostic value of PLR in various cancers $(7,37)$. A meta-analysis including 11 studies 


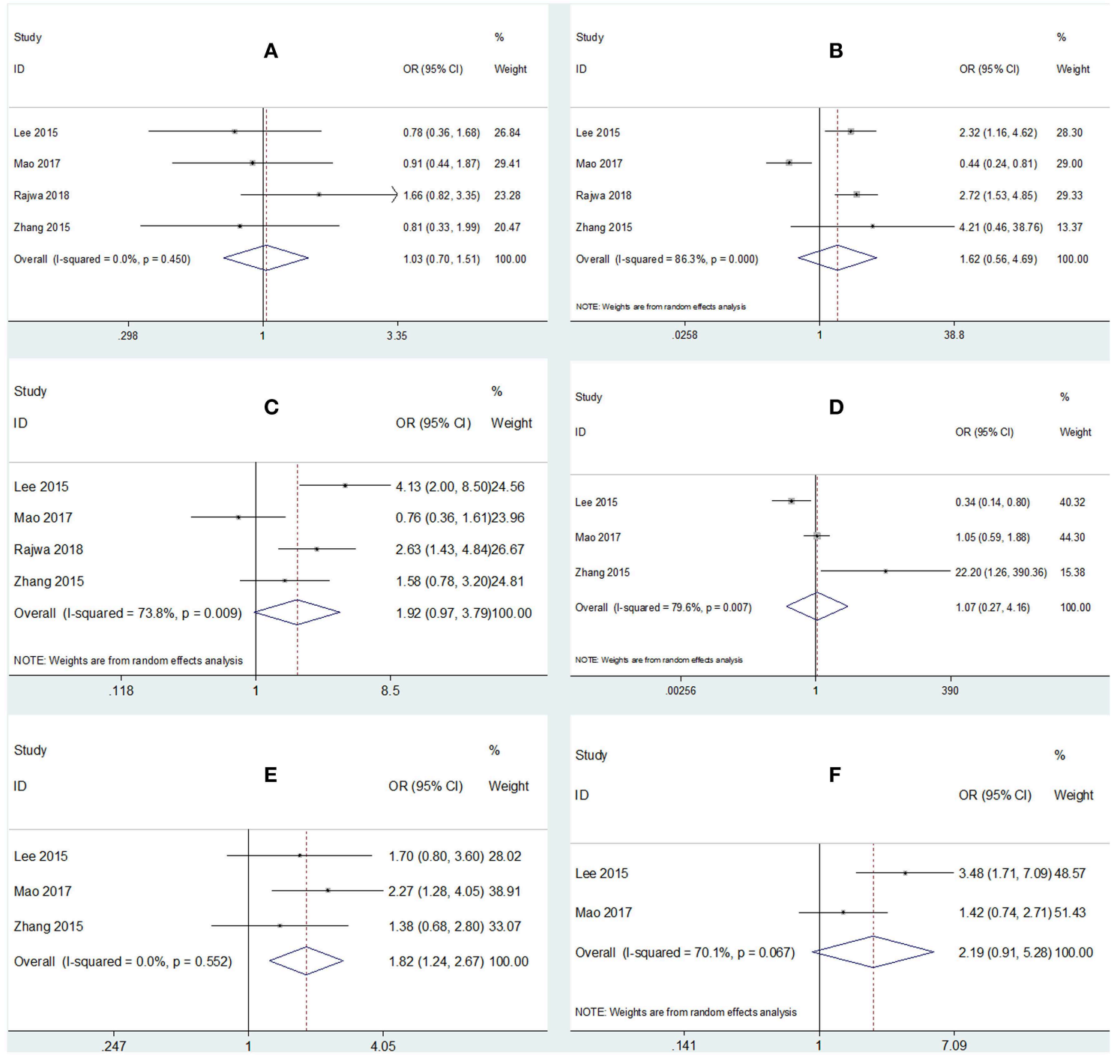

FIGURE 3 | Forrest plots of associations between PLR and (A) sex, (B) tumor grade, (C) tumor stage, (D) distant metastasis, (E) age, and (F) tumor size.

showed that elevated PLR was associated with shorter OS (HR: 1.48, 95\% CI: $1.24-1.76, p<0.001)$ in patients with ovarian cancer (38). Li's work also demonstrated an elevated PLR was associated with unfavorable overall survival in patients with pancreatic cancer (39). Another recent study indicated that an elevated PLR was an effective prognostic marker of both OS (pooled HR $=2.10,95 \%$ CI: $1.38-3.19, p=0.001$ ) and progression-free survival (PFS) (pooled HR $=3.45,95 \%$ CI: 1.61 7.40, $p=0.001$ ) in renal cell carcinoma (40). In the present meta-analysis, we found the prognostic role of PLR for poorer OS, which was in accordance with previous studies. Furthermore, we also identified the association of PLR and older age, which may emphases the prognostic value of PLR in aged bladder cancer patients.

This meta-analysis showed that high PLR predicted poor OS, but not CSS nor RFS. We think this finding may be correlated with the amount of included studies and duration of followup. First, 7 studies were included for OS analysis, whereas only 4 and 2 studies were included for CSS and RFS analysis. Because less studies were included, the pooled results may be at the risk of more bias, which is a possible reason for nonsignificant correlation of PLR and CSS or RFS. Second, we think it is more important, is the different duration of followup for OS, CSS, and RFS. For the same group of patients, the OS is regularly longer than CSS and RFS. A high PLR predicted poor OS, but not CSS nor RFS, which could be possibly explained by that PLR reflected the balance status of immune responses and cancer development. The clinical significance of PLR is emerging at a relatively long duration at course of disease, such as OS. Because the follow-ups of CSS and RFS is relatively short, so the prognostic value of PLR could be non-significant. 
TABLE 3 | Meta-analysis results of PLR and clinicopathological parameters in patients with bladder cancer.

\begin{tabular}{|c|c|c|c|c|c|c|}
\hline Clinicopathological factors & No. of studies & OR (95\% Cl) & $p$ & $I^{2}(\%)$ & $\boldsymbol{P}$-value for heterogeneity & Analysis model \\
\hline $\operatorname{Sex}(M$ vs. F) & 4 & $1.03(0.7-1.51)$ & 0.884 & 0 & 0.45 & Fixed \\
\hline Tumor grade (G3 vs. G1/G2) & 4 & $1.62(0.56-4.69)$ & 0.373 & 86.3 & $<0.001$ & Random \\
\hline Tumor stage (T2-T4 vs. Ta-T1) & 4 & $1.92(0.97-3.79)$ & 0.06 & 73.8 & 0.009 & Random \\
\hline Distant metastasis (yes vs. no) & 3 & $1.07(0.27-4.16)$ & 0.927 & 79.6 & 0.007 & Random \\
\hline Age (y) $(\geq 65$ vs. $<65)$ & 3 & $1.82(1.24-2.67)$ & 0.002 & 0 & 0.552 & Fixed \\
\hline Tumor size (cm) ( $\geq 3$ vs. $<3$ ) & 2 & $2.19(0.91-5.28)$ & 0.08 & 70.1 & 0.067 & Random \\
\hline
\end{tabular}

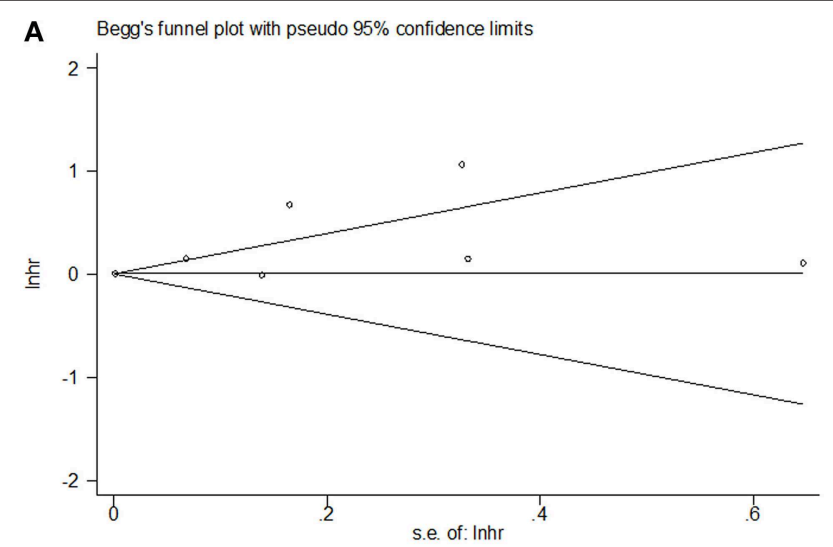

B Begg's funnel plot with pseudo $95 \%$ confidence limits

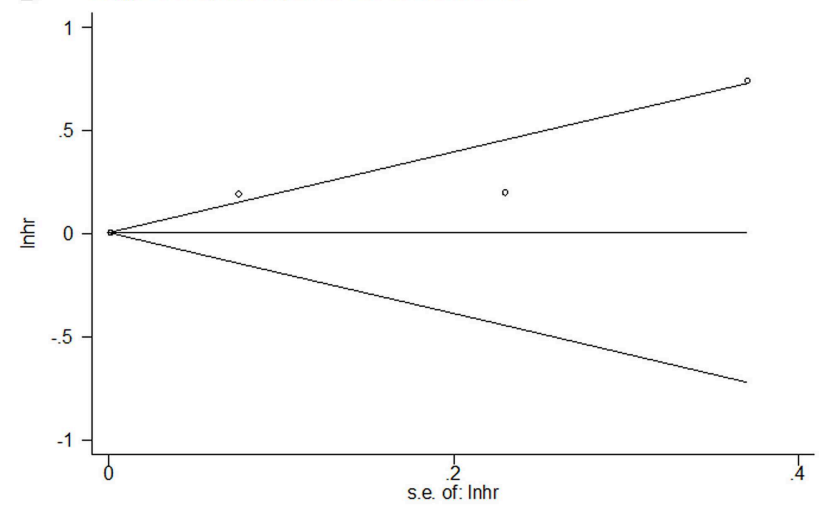

C Begg's funnel plot with pseudo $95 \%$ confidence limits

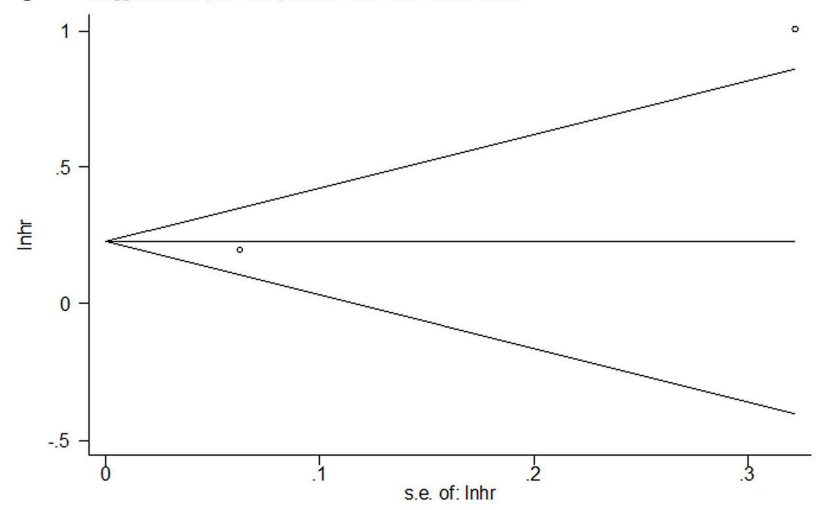

FIGURE 4 | Begg's funnel plots of (A) OS, (B) CSS, and (C) RFS.
It is notable that the results showed that PLR was significantly associated with age $\geq 65$ years $(p=0.002)$. Because as age advances, the immune system undergoes profound remodeling and decline (41). The immune responses in elderly patients were weaken compared to patients in middle age (41). We think this is the possible reason for the association between high PLR and old age. It is also possible that PLR and old age are cofound factors for poor OS. Actually, a high PLR was also associated with higher tumor stage $(p=0.06)$ and larger tumor size $(p=0.08)$, although they are not statistically significant. The correlation might be significant when more studies were included. Taken together, we think it is reasonable that PLR is associated with older age, but PLR might not simply be a surrogate for age. PLR is possible associated with other aggressive clinical factors when more studies were included. In the current meta-analysis, all included studies applied surgery for bladder cancer patients. Therefore, we recommend that PLR should be evaluated at diagnosis of MIBC, or before surgery. Patients with greater PLR $(\geq 150)$ might be treated with more aggressive therapeutic strategies or at close follow-up after curative treatment. In addition, because all included studies used surgical resection, the impact of chemotherapy or radiation therapy could not be investigated in the current meta-analysis. Further studies on the impact of chemotherapy or radiotherapy on PLR are still needed.

Nevertheless, our study has several limitations. First, significant heterogeneity existed among studies. However, subgroup analyses showed that the heterogeneity disappeared in studies with PLR cut-off value $<150$ and studies with sample size $\geq 200$. Second, the cut-off value of PLR applied in included studies was not uniform. Third, a large part of the included studies come from Asia. It is unclear whether these findings apply to other populations. Finally, all included studies were retrospective studies. Therefore, further large-scale prospective studies are needed to validate the results.

\section{CONCLUSION}

Our results demonstrated that the pretreatment PLR was associated with worse OS in conjunction with older age clinicopathological features in patients with bladder cancer. Therefore, it is suggested that PLR is a promising biomarker 
for use in clinical management to predict survival outcome in bladder cancer.

\section{AUTHOR CONTRIBUTIONS}

GT collected and analyzed the data and wrote the paper. XW analyzed the data and participated in the writing of manuscript. $\mathrm{XN}$ assisted with the data analyses. XW and GT conceived and

\section{REFERENCES}

1. Bray F, Ferlay J, Soerjomataram I, Siegel RL, Torre LA, Jemal A. Global cancer statistics 2018: GLOBOCAN estimates of incidence and mortality worldwide for 36 cancers in 185 countries. CA Cancer J Clin. (2018) 68:394424. doi: $10.3322 /$ caac. 21492

2. Kamat AM, Hahn NM, Efstathiou JA, Lerner SP, Malmstrom PU, Choi W, et al. Bladder cancer. Lancet. (2016) 388:2796810. doi: 10.1016/S0140-6736(16)30512-8

3. Froehner M, Novotny V, Heberling U, Rutsch L, Litz RJ, Hubler M, et al. Relationship of the number of removed lymph nodes to bladder cancer and competing mortality after radical cystectomy. Eur Urol. (2014) 66:98790. doi: 10.1016/j.eururo.2014.07.046

4. Kluth LA, Black PC, Bochner BH, Catto J, Lerner SP, Stenzl A, et al. Prognostic and prediction tools in bladder cancer: a comprehensive review of the literature. Eur Urol. (2015) 68:238-53. doi: 10.1016/j.eururo.2015.01.032

5. Grivennikov SI, Greten FR, Karin M. Immunity, inflammation, and cancer. Cell. (2010) 140:883-99. doi: 10.1016/j.cell.2010.01.025

6. Templeton AJ, McNamara MG, Seruga B, Vera-Badillo FE, Aneja P, Ocana A, et al. Prognostic role of neutrophil-to-lymphocyte ratio in solid tumors: a systematic review and meta-analysis. J Natl Cancer Inst. (2014) 106:dju124. doi: 10.1093/jnci/dju124

7. Zhou X, Du YP, Huang ZB, Xu J, Qiu TZ, Wang J, et al. Prognostic value of PLR in various cancers: a meta-analysis. PLoS ONE. (2014) 9:e101119. doi: 10.1371/journal.pone.0101119

8. Li B, Zhou PT, Liu YJ, Wei HF, Yang XH, Chen TR, et al. Platelet-tolymphocyte ratio in advanced cancer: review and meta-analysis. Clin Chim Acta. (2018) 483:48-56. doi: 10.1016/j.cca.2018.04.023

9. Teng JJ, Zhang J, Zhang TY, Zhang S, Li BS. Prognostic value of peripheral blood lymphocyte-to-monocyte ratio in patients with solid tumors: a metaanalysis. Onco Targets Ther. (2016) 9:37-47. doi: 10.2147/OTT.S94458

10. Zhao YZ, Si GY, Zhu FS, Hui JL, Cai SL, Huang CS, et al. Prognostic role of platelet to lymphocyte ratio in hepatocellular carcinoma: a systematic review and meta-analysis. Oncotarget. (2017) 8:22854-62. doi: 10.18632/oncotarget.15281

11. Zhang $M$, Huang XZ, Song YX, Gao P, Sun JX, Wang ZN. High platelet-to-lymphocyte ratio predicts poor prognosis and clinicopathological characteristics in patients with breast cancer: a meta-analysis. Biomed Res Int. (2017) 2017:9503025. doi: 10.1155/2017/9503025

12. Min GT, Wang YH, Yao N, Zhao JM, Wang J, Wang HP, et al. The prognostic role of pretreatment platelet-to-lymphocyte ratio as predictors in patients with colorectal cancer: a meta-analysis. Biomarkers Med. (2017) 11:87-97. doi: 10.2217/bmm-2016-0181

13. Wang JF, Zhou XF, He YH, Chen X, Liu NB, Ding ZS, et al. Prognostic role of platelet to lymphocyte ratio in prostate cancer a meta-analysis. Medicine. (2018) 97:e12504. doi: 10.1097/MD.0000000000012504

14. Zhao QT, Yuan Z, Zhang H, Zhang XP, Wang HE, Wang ZK, et al. Prognostic role of platelet to lymphocyte ratio in non-small cell lung cancers: a meta-analysis including 3,720 patients. Int J Cancer. (2016) 139:16470. doi: 10.1002/ijc. 30060

15. Lee SM, Russell A, Hellawell G. Predictive value of pretreatment inflammation-based prognostic scores (neutrophil-to-lymphocyte ratio, platelet-to-lymphocyte ratio, and lymphocyte-to-monocyte ratio) for invasive bladder carcinoma. Korean J Urol. (2015) 56:749-55. doi: 10.4111/kju.2015.56.11.749 designed this study. All authors reviewed the paper, read, and approved the final manuscript.

\section{FUNDING}

This article was supported by the Public Welfare Project of Shaoxing Science and Technology Bureau (No. 2017B70035).
16. Bhindi B, Hermanns T, Wei YL, Yu JL, Richard PO, Wettstein MS, et al. Identification of the best complete blood count-based predictors for bladder cancer outcomes in patients undergoing radical cystectomy. $\mathrm{Br} J$ Cancer. (2016) 114:207-12. doi: 10.1038/bjc.2015.432

17. Kang M, Jeong CW, Kwak C, Kim HH, Ku JH. Preoperative neutrophil-lymphocyte ratio can significantly predict mortality outcomes in patients with non-muscle invasive bladder cancer undergoing transurethral resection of bladder tumor. Oncotarget. (2017) 8:12891-901. doi: 10.18632/oncotarget.14179

18. Mao SY, Huang TB, Xiong DD, Liu MN, Cai KK, Yao XD. Prognostic value of preoperative systemic inflammatory responses in patients with non-muscle invasive bladder cancer undergoing transurethral resection of bladder tumor. Int J Clin Exp Pathol. (2017) 10:5799-810.

19. Miyake M, Morizawa Y, Hori S, Marugami N, Iida K, Ohnishi K, et al. Integrative assessment of pretreatment inflammation-, nutrition-, and muscle-based prognostic markers in patients with muscle-invasive bladder cancer undergoing radical cystectomy. Oncology. (2017) 93:25969. doi: $10.1159 / 000477405$

20. Moher D, Liberati A, Tetzlaff J, Altman DG, Grp P. Preferred reporting items for systematic reviews and meta-analyses: the PRISMA statement. Ann Intern Med. (2009) 151:264. doi: 10.7326/0003-4819-151-4-200908180-00135

21. Stang A. Critical evaluation of the Newcastle-Ottawa scale for the assessment of the quality of nonrandomized studies in meta-analyses. Eur J Epidemiol. (2010) 25:603-5. doi: 10.1007/s10654-010-9491-z

22. DerSimonian R, Laird N. Meta-analysis in clinical trials. Control Clin Trials. (1986) 7:177-88. doi: 10.1016/0197-2456(86)90046-2

23. Mantel N, Haenszel W. Statistical aspects of the analysis of data from retrospective studies of disease. J Natl Cancer Inst. (1959) 22:719-48.

24. Begg CB, Mazumdar M. Operating characteristics of a rank correlation test for publication bias. Biometrics. (1994) 50:1088-101. doi: 10.2307/2533446

25. Zhang GM, Zhu Y, Luo L, Wan FN, Zhu YP, Sun LJ, et al. Preoperative lymphocyte-monocyte and platelet-lymphocyte ratios as predictors of overall survival in patients with bladder cancer undergoing radical cystectomy. Tumour Biol. (2015) 36:8537-43. doi: 10.1007/s13277-015-3613-x

26. Peng D, Zhang CJ, Gong YQ, Hao H, Guan B, Li XS, et al. Prognostic significance of HALP (hemoglobin, albumin, lymphocyte and platelet) in patients with bladder cancer after radical cystectomy. Sci Rep. (2018) 8:794. doi: 10.1038/s41598-018-19146-y

27. Rajwa P, Zyczkowski M, Paradysz A, Bujak K, Bryniarski P. Evaluation of the prognostic value of LMR, PLR, NLR, and dNLR in urothelial bladder cancer patients treated with radical cystectomy. Eur Rev Med Pharmacol Sci. (2018) 22:3027-37. doi: 10.26355/eurrev_201805_15060

28. Coussens LM, Werb Z. Inflammation and cancer. Nature. (2002) 420:8607. doi: $10.1038 /$ nature 01322

29. Mantovani A, Allavena P, Sica A, Balkwill F. Cancer-related inflammation. Nature. (2008) 454:436-44. doi: 10.1038/nature07205

30. Goubran HA, Burnouf T, Radosevic M, El-Ekiaby M. The platelet-cancer loop. Eur J Intern Med. (2013) 24:393-400. doi: 10.1016/j.ejim.2013.01.017

31. Goubran HA, Stakiw J, Radosevic M, Bumouf T. Platelets effects on tumor growth. Semin Oncol. (2014) 41:35969. doi: 10.1053/j.seminoncol.2014.04.006

32. Goubran HA, Stakiw J, Radosevic M, Burnouf T. Platelet-cancer interactions Semin Thromb Hemost. (2014) 40:296-305. doi: 10.1055/s-0034-1370767

33. Janowska-Wieczorek A, Wysoczynski M, Kijowski J, Marquez-Curtis L, Machalinski B, Ratajczak J, et al. Microvesicles derived from activated platelets 
induce metastasis and angiogenesis in lung cancer. Int J Cancer. (2005) 113:752-60. doi: 10.1002/ijc.20657

34. Schumacher D, Strilic B, Sivaraj KK, Wettschureck N, Offermanns S. Platelet-derived nucleotides promote tumor-cell transendothelial migration and metastasis via P2Y2 receptor. Cancer Cell. (2013) 24:130-7. doi: 10.1016/j.ccr.2013.05.008

35. Elinav E, Nowarski R, Thaiss CA, Hu B, Jin C, Flavell RA. Inflammationinduced cancer: crosstalk between tumours, immune cells and microorganisms. Nat Rev Cancer. (2013) 13:759-71. doi: 10.1038/nrc3611

36. Mahmoud SM, Paish EC, Powe DG, Macmillan RD, Grainge MJ, Lee $\mathrm{AH}$, et al. Tumor-infiltrating CD8+ lymphocytes predict clinical outcome in breast cancer. J Clin Oncol. (2011) 29:1949-55. doi: 10.1200/JCO.2010. 30.5037

37. Templeton AJ, Ace O, McNamara MG, Al-Mubarak M, Vera-Badillo FE, Hermanns T, et al. Prognostic role of platelet to lymphocyte ratio in solid tumors: a systematic review and meta-analysis. Cancer Epidemiol Biomarkers Prev. (2014) 23:1204-12. doi: 10.1158/1055-9965.EPI-14-0146

38. Tian C, Song W, Tian X, Sun Y. Prognostic significance of platelet-to-lymphocyte ratio in patients with ovarian cancer: a meta-analysis. Eur J Clin Invest. (2018) 48:e12917. doi: 10.1111/eci. 12917
39. Li WD, Tao LY, Lu M, Xiu DR. Prognostic role of platelet to lymphocyte ratio in pancreatic cancers a meta-analysis including 3028 patients. Medicine. (2018) 97:e9616. doi: 10.1097/MD.0000000000009616

40. Wang Z, Peng SH, Wang AX, Xie H, Guo LP, Jiang N, et al. Plateletlymphocyte ratio acts as an independent predictor of prognosis in patients with renal cell carcinoma. Clin Chim Acta. (2018) 480:16672. doi: 10.1016/j.cca.2018.02.014

41. Simon AK, Hollander GA, McMichael A. Evolution of the immune system in humans from infancy to old age. Proc $R$ Soc B Biol Sci. (2015) 282:9. doi: $10.1098 / \mathrm{rspb} .2014 .3085$

Conflict of Interest Statement: The authors declare that the research was conducted in the absence of any commercial or financial relationships that could be construed as a potential conflict of interest.

Copyright (๑) 2019 Wang, Ni and Tang. This is an open-access article distributed under the terms of the Creative Commons Attribution License (CC BY). The use, distribution or reproduction in other forums is permitted, provided the original author(s) and the copyright owner(s) are credited and that the original publication in this journal is cited, in accordance with accepted academic practice. No use, distribution or reproduction is permitted which does not comply with these terms. 